\title{
The impact of osteoarthritis on early exit from work: results from a population-based study
}

Pedro A. Laires ${ }^{1,2,3^{*}}$, Helena Canhão ${ }^{3,4}$, Ana M. Rodrigues ${ }^{1,3}$, Mónica Eusébio ${ }^{3}$, Miguel Gouveia ${ }^{5}$ and Jaime C. Branco $3,4,6$

\begin{abstract}
Background: Osteoarthritis $(\mathrm{OA})$ is a leading cause of pain and disability, which may be a source of productivity losses. The objectives of this study were to describe the impact of OA, namely through pain and physical disability, on early exit from work and to calculate its economic burden.

Methods: We analysed data from the national, cross-sectional, population-based EpiReumaPt study (Sep2011-Dec2013) in which 10,661 individuals were randomly surveyed in order to capture all cases of rheumatic diseases. We used all participants aged 50-64, near the official retirement age, who were clinically validated by experienced rheumatologists $(n=1286)$, including OA cases. A national database was used to calculate productivity values by gender, age and region, using the human capital approach. The impact of OA on the likelihood of early exit from work and the population attributable fractions used to calculate due economic burden (indirect costs) were obtained at the individual level by logistic regression. All results were based on weighted data.

Results: Almost one third of the Portuguese population aged 50-64 had OA (29.7\%; men: 16.2\% and women: 43.5\%) and more than half were out of paid work (51.8\%). Only knee OA is associated with early exit from work (OR: 2.25; 95\%Cl: 1.42-3.59; $p=0.001$ ), whereas other OA locations did not reach any statistical difference. Furthermore, we observed an association between self-reported longstanding musculoskeletal pain (OR: 1.55; 95\%Cl: 1.07-2.23; $p=0.02$ ) and pain interference (OR: 1.35; 95\%Cl: 1.13-1.62; $p=0.001$ ) with early exit from work. We also detected a clear relationship between levels of disability, measured by the Health Assessment Questionnaire (HAQ), and the probability of work withdrawal. The estimated annual cost of early exit from work attributable to OA was €656 million (€384 per capita; €1294 per OA patient and €2095 per OA patient out-of-work).
\end{abstract}

Conclusions: In this study, we observed an association between OA and early exit from work, largely dependent on pain and disability. This relationship translates into a meaningful economic burden amounting to approximately $0.4 \%$ of the national Gross Domestic Product (GDP). The high prevalence and the impact of this disabling chronic disease highlight the need to prioritize policies targeting early exit from work in OA.

Keywords: Exit from work, Early Retirement, Work disability, Indirect costs, Cost of illness, Economic impact, Health Survey, Osteoarthritis

\footnotetext{
* Correspondence: laires.pedro@gmail.com

${ }^{1}$ Faculdade de Medicina da Universidade de Lisboa, Lisbon Academic

Medical Center, Lisbon, Portugal

${ }^{2}$ Centro de Investigação em Saúde Pública, Escola Nacional de Saúde

Pública, Lisbon, Portugal

Full list of author information is available at the end of the article
} 


\section{Background}

Osteoarthritis (OA) is a degenerative joint disorder and the most common form of arthritis in adults [1]. It is characterized by pain and functional impairment, which may lead to disability, including work restriction [2-4].

In many western countries the population is ageing due to increasing longevity and falling birth rates [5]. Portugal, for instance, is amongst the oldest countries in the world, and has one of the highest old-age dependency ratios, further aggravated by the fact that currently unemployment and overall premature work withdrawal are still high [6].

Numerous factors, including health-related problems, may contribute to the high rate of exit from the workforce that persists at a global level [7-11]. In fact, several studies have already shown that ill-health is a risk factor for early exit from work, including retirement and unemployment $[12,13,16]$. A deeper understanding of these factors is crucial to support policies for increasing productivity and postponing exit from work.

The growing prevalence of chronic disabling diseases, such as OA, jeopardizes any effort to prolong the working life of the labour force of modern societies. In spite of this, research about the effect of OA on work participation and its economic burden is still lacking $[14,15]$.

Thus, the objectives of this study were to describe the impact of OA, namely through pain and physical disability, on early exit from work and to calculate its economic burden.

\section{Methods}

\section{Sample}

This study uses the first national, cross-sectional, population-based study on rheumatic diseases in Portugal - the EpiReumaPt study [16]. The methodology of EpiReumaPt has been detailed elsewhere [17]. Briefly, EpiReumaPt (September 2011-December 2013) randomly selected a representative sample of 10,661 adult subjects who self-reported several data following a questionnaire applied by trained staff. Rheumatologists then performed a standardized physical examination and appropriate laboratory/imaging evaluation on those participants with rheumatic complaints/symptoms.

For the purposes of this analysis we used data from EpiReumaPt participants aged between 50 and 64 years old, near the official retirement age, who were clinically evaluated by the rheumatologists $(n=1286)$.

\section{Measures}

We considered the presence of OA through clinical confirmation initially done by a rheumatologist and then validated by a team of three experienced rheumatologists, in accordance with the American College of Rheumatology (ACR) classification criteria, of at least one type of OA: knee OA [18], hip OA [19], and hand OA [20]. All those without any of these OA types were considered to be non-OA.

The following self-reported measures were used: major chronic diseases (rheumatic diseases, diabetes, cardiovascular diseases including risk factors such as hypertension and high cholesterol, allergy, pulmonary disease, gastrointestinal disease, neurological disease, mental disease, and cancer); comorbidity score (built as the sum of all aforementioned chronic illnesses); body mass index (BMI, derived from selfreported height and weight and categorized as underweight: $<18.5 \mathrm{~m}^{2} / \mathrm{kg}$, normal: $18.5-25 \mathrm{~m}^{2} / \mathrm{kg}$, overweight: $25-30 \mathrm{~m}^{2} / \mathrm{kg}$ and obese: $\geq 30 \mathrm{~m}^{2} / \mathrm{kg}$ ); quality of life (using the final 0-100 score from the SF-36 Health Survey [21, 22] and its eight items separately, including the bodily pain; and the European Quality of Life questionnaire with five dimensions and three levels validated for Portugal, EQ-5D index [23, 24]); longstanding musculoskeletal pain ( $\geq 3$ months); pain interference with function (i.e. pain affecting labour and domestic activities based on the SF36 question: During the past 4 weeks, how much did pain interfere with your normal work, including both work outside the home and housework?); functional capacity (0-3 score from the Health Assessment Questionnaire, HAQ [25]); marital status; household monthly income; and educational level (classified into three major levels according to the highest degree completed: primary school or less, basic education between primary and secondary levels, and secondary education or more, including university degrees). Since the underlying etiological model of this research, which connects OA with early exit from work, comprises pain and disability as important intermediate steps, we analysed them in further detail by using the abovementioned instruments.

Regarding the case definition for the main outcome, individuals were asked directly about their employment status and all those who did not report any kind of paid work (part- or full-time), including students, housekeepers or anyone without a regular salary; as well as those in official early retirement or disability pensions, were included in the early exit from paid employment group. All those reporting any form of regularly paid work were considered employed. This definition was used elsewhere in earlier research $[1,26]$.

A broader definition of early withdrawal from work allows us to take into account the existence of different pathways to early retirement. However, we also 
considered it relevant to separately analyse more specific types of exit from work, including official early retirement and unemployment.

\section{Economic burden (INDIRECT COSTS)}

In order to calculate the productivity loss (indirect costs) of early exit from work attributable to OA in Portugal's mainland we adopted the society's perspective, which considers the aggregate value of indirect costs for all parts in the Society (including patients, employers, and the government), and used the human capital approach. This method estimates productivity by valuing healthy time lost due to OA using market wage rates, which can be viewed as the loss of an investment in a person's human capital [27]. Early exit from paid employment associated with OA was assessed through logistic regression models. A good measure of the impact of $\mathrm{OA}$ in the early exit from work may be the population attributable fractions (PAF), which take into account both the strength of the association between OA and early exit from work, as measured in the logistic regression models, and the prevalence of $\mathrm{OA}$ in the population surveyed. PAF were calculated as the resulting proportional change in the probability of premature work withdrawal following a counterfactual exercise in which the presence of $\mathrm{OA}$ was artificially eliminated from the sample. This recalculated probability of exit from work was then used to estimate the indirect costs attributable to OA by multiplying each observation's probability change with the corresponding unit value of production. The unit values of production were assessed by obtaining the market wage rates from national public sources [28]. These figures needed to be grossed up by social security contributions. This approach yielded an annual average value of $€ 24,891$ for men and $€ 16,079$ for women, for ages between 50 and 64. All unit values of production were stratified by age, gender, and geographic region (Appendix 1).

\section{Statistical analysis}

Descriptive analysis was mainly performed by comparing early withdrawals from work (including early retirees) versus the employed participants of the sample analysed. Prevalence of early exit from work and other characteristics were computed as weighted data, in order to take into account the stratified sampling design of the survey. Missing values were not replaced and all statistics were calculated based on non-missing values. To explore the association between OA and early exit from work we built multivariable logistic regression models by means of a manual stepwise technique (backward elimination) using the following potential confounders: age, gender, region, marital status, education, household income, BMI, and chronic diseases. Pain and disability were not included in the multivariable models since they are considered intermediate factors of OA within the etiologic model adopted [29, 30]. Their association with the outcome was instead analysed separately adjusted for age, gender, and region. All statistical analyses were carried out using Stata IC V.12 (StataCorp, 2011. Stata Statistical Software: Release 12. College Station, Texas, USA: StataCorp LP).

\section{Results}

Amongst the survey respondents, more than half of the population aged between 50 and 64 years were out of paid work $(51.8 \%$. Table 1$)$ and had an OA prevalence of about 30\% (29.7\%; men: $16.2 \%$ and women: $43.5 \%$. Knee OA: 18.6\%; hand: $12.6 \%$; hip: 3 . $6 \%)$. Lower education and monthly household income were more frequent in the premature withdrawals, whilst the marital status single was more likely found in the employed. The out-of-work group had a poorer health status, with higher comorbidity scores, lower quality of life, and lower functional capacity. Higher prevalence of diabetes and neurological disorders were also found in this group. In comparison to the paid employment group, OA prevalence was significantly higher in all other groups (Table 1).

The participants with OA had more comorbidities (Comorbidity score: 2.3 vs $1.7 ; p<0.001$. Table 2 ), in particular diabetes, gastrointestinal and mental disorders, and were more likely to self-report other main chronic diseases (age, gender, and region adjusted OR: 1.70 ; CI: $1.07-2.69 ; p=0.023)$. OA participants had poorer quality of life measured by all SF-36 items, especially the bodily pain index (54.9 vs. $72.6, p<0.001)$, and by the EQ-5D score $(0.68$ vs. $0.83 ; p<0.001)$. OA patients more frequently reported longstanding musculoskeletal pain than non-OA $(52.5 \%$ vs. $34.1 \%$; p $<0.001)$. The OA population also scored worse in functional capacity measured by the HAQ scale $(0.64$ vs. $0.28 ; p<0.001)$. This is especially true for the knee OA location (mean score: 0.61, 95\%CI: 0.53-0.69). Within the OA group, $61.8 \%$ were not working versus $47.6 \%$ for those without OA $(p=0.004)$. Most were females (71.0\% versus $41.9 \%$ for those non-OA in the outof-work group; $p<0.001$ ). A non-significant difference was observed when analysing early retirement specifically $(32.6 \%$ vs. $29.1 \%$, respectively; $p=0.437$. Table 2). Unemployment is a major early route of work loss in the OA population $(17.7 \%$ vs. $9.9 \%$ for non-OA; $p=0.002)$. The vast majority of registered unemployment lasted more than 12 months (95.8\%). 
Table 1 General description of the sample by employment status: EpiReumaPt ages 50-64 ( $n=1286)$

\begin{tabular}{|c|c|c|c|c|}
\hline & UNEMPLOYMENT & EARLY RETIREMENT & EXIT FROM WORK & PAID EMPLOYMENT \\
\hline Employment Status & $12.2 \%$ & $30.2 \%$ & $51.8 \%$ & $48.2 \%$ \\
\hline Age (years) & $55.2(p=0.192)^{*}$ & $59.9(p<0.001)^{*}$ & $58.2(p<0.001)^{*}$ & 54.6 \\
\hline Gender (female) & $55.3 \%(p=0.187)$ & $44.2 \%(p=0.757)$ & $52.2 \%(p=0.305)$ & $46.3 \%$ \\
\hline \multicolumn{5}{|l|}{ Marital Status } \\
\hline Single & $11.7 \%$ & $3.4 \%$ & $5.7 \%$ & $14.9 \%$ \\
\hline Married/Consensual union & $70.6 \%$ & $77.3 \%$ & $76.2 \%$ & $64.5 \%$ \\
\hline Divorced & $14.3 \%$ & $10.4 \%$ & $10.3 \%$ & $15.3 \%$ \\
\hline Widowed & $3.4 \%(p=0.673)$ & $8.9 \%(p=0.002)$ & $7.8 \%(p=0.007)$ & $5.2 \%$ \\
\hline \multicolumn{5}{|l|}{ Body Mass Index } \\
\hline Underweight $\left(<18.5 \mathrm{~m}^{2} / \mathrm{kg}\right)$ & $0 \%$ & $0.5 \%$ & $0.5 \%$ & $0.4 \%$ \\
\hline Normal $\left(18.5-25 \mathrm{~m}^{2} / \mathrm{kg}\right)$ & $28.5 \%$ & $25.7 \%$ & $27.0 \%$ & $30.5 \%$ \\
\hline Overweight $\left(25-30 \mathrm{~m}^{2} / \mathrm{kg}\right)$ & $44.6 \%$ & $50.3 \%$ & $46.3 \%$ & $46.7 \%$ \\
\hline Obese $\left(\geq 30 \mathrm{~m}^{2} / \mathrm{kg}\right)$ & $27.7 \%(p=0.788)$ & $23.5 \%(p=0.801)$ & $26.2 \%(p=0.762)$ & $22.4 \%$ \\
\hline Clinically Confirmed OA & $42.8 \%(p<0.001)$ & $32.1 \%(p=0.08)$ & $35.4 \%(p=0.003)$ & $23.5 \%$ \\
\hline Knee OA & $29.0 \%(p<0.001)$ & $22.0 \%(p=0.005)$ & $24.2 \%(p<0.001)$ & $12.6 \%$ \\
\hline Hand OA & $14.3 \%(p=0.413)$ & $12.3 \%(p=0.797)$ & $13.6 \%(p=0.405)$ & $11.6 \%$ \\
\hline Hip OA & $3.1 \%(p=0.795)$ & $4.2 \%(p=0.809)$ & $3.6 \%(p=0.998)$ & $3.6 \%$ \\
\hline \multicolumn{5}{|l|}{ Chronic Diseases (self-reported) } \\
\hline Cardiovascular & $60.6 \%(p=0.740)$ & $62.8 \%(p=0.991)$ & $63.7 \%(p=0.874)$ & $62.8 \%$ \\
\hline Diabetes & $10.1 \%(p=0.180)$ & $17.5 \%(p=0.003)$ & $15.9 \%(p<0.001)$ & $6.4 \%$ \\
\hline Pulmonary & $11.5 \%(p=0.147)$ & $7.5 \%(p=0.407)$ & $9.9 \%(p=0.110)$ & $5.0 \%$ \\
\hline Allergy & $22.4 \%(p=0.411)$ & $20.5 \%(p=0.242)$ & $22.4 \%(p=0.356)$ & $27.5 \%$ \\
\hline Gastrointestinal & $22.6 \%(p=0.460)$ & $26.6 \%(p=0.114)$ & $25.5 \%(p=0.102)$ & $19.1 \%$ \\
\hline Neoplasic & $5.9 \%(p=0.458)$ & $6.5 \%(p=0.282)$ & $5.7 \%(p=0.338)$ & $3.9 \%$ \\
\hline Mental & $15.8 \%(p=0.493)$ & $13.6 \%(p=0.942)$ & $17.2 \%(p=0.130)$ & $13.4 \%$ \\
\hline Neurologic & $1.6 \%(p=0.644)$ & $6.7 \%(p=0.005)$ & $4.8 \%(p=0.004)$ & $1.2 \%$ \\
\hline Comorbidity Score & $1.87(p=0.471)$ & $2.03(p=0.10)$ & $2.04(p=0.03)$ & 1.74 \\
\hline Longstanding Musculoskeletal Pain & $47.0 \%(p=0.049)$ & $39.7 \%(p=0.399)$ & $43.9 \%(p=0.073)$ & $34.8 \%$ \\
\hline Functional Capacity - HAQ & $0.48(p=0.012)$ & $0.43(p=0.033)$ & $0.47(p=0.002)$ & 0.28 \\
\hline Quality of Life - EQ-5D & $0.72(p<0.001)$ & $0.79(p=0.152)$ & $0.75(p=0.002)$ & 0.83 \\
\hline \multicolumn{5}{|l|}{ Educational Level } \\
\hline Primary or less & $55.0 \%$ & $64.0 \%$ & $63.4 \%$ & $37.3 \%$ \\
\hline Medium & $23.3 \%$ & $17.6 \%$ & $19.6 \%$ & $28.5 \%$ \\
\hline High & $21.7 \%(p=0.024)$ & $18.4 \%(p<0.001)$ & $17.0 \%(p<0.001)$ & $34.2 \%$ \\
\hline \multicolumn{5}{|l|}{ Monthly Household Income } \\
\hline$\leq € 500$ & $49.2 \%$ & $22.3 \%$ & $29.8 \%$ & $12.1 \%$ \\
\hline$€ 501-€ 1000$ & $36.3 \%$ & $37.6 \%$ & $40.7 \%$ & $38.6 \%$ \\
\hline$€ 1001-€ 2000$ & $8.5 \%$ & $28.7 \%$ & $20.7 \%$ & $33.1 \%$ \\
\hline$>€ 2000$ & $6.0 \%(p<0.001)$ & $11.4 \%(p=0.243)$ & $8.8 \%(p=0.001)$ & $16.2 \%$ \\
\hline
\end{tabular}

All results were computed as weighted proportions to keep in account the sampling design of the survey

*all $p$ values versus paid employment. OA, Osteoarthritis; HAQ, Health Assessment Questionnaire; EQ-5D, European Quality of Life index

Figure 1 shows how unemployment rates were high amongst the youngest of the OA population (i.e. 50-56) whilst being surpassed by official early retirement after approximately the age of 56 . A distinct dynamic is observed in the non-OA population, in which unemployment rates are in line with early retirement below age 55 . 
Table 2 Description of the sample by OA diagnosis, including pain, functional status and quality of life results (SF-36 and EQ-5D): EpiReumaPt ages 50-64 $(n=1286)$

\begin{tabular}{|c|c|c|}
\hline & $\mathrm{OA}(n=382)$ & $\mathrm{NON}-\mathrm{OA}(n=904)$ \\
\hline Age (years) & 57.5 & $56.0(p<0.001)^{*}$ \\
\hline Gender (female) & $72.3 \%$ & $39.6 \%(p<0.001)$ \\
\hline \multicolumn{3}{|l|}{ Employment Status } \\
\hline Unemployment & $17.7 \%$ & $9.9 \%(p=0.002)$ \\
\hline Early Retirement & $32.6 \%$ & $29.1 \%(p=0.437)$ \\
\hline Exit from Work & $61.8 \%$ & $47.6 \%(p=0.004)$ \\
\hline \multicolumn{3}{|l|}{ Educational Level } \\
\hline Primary or less & $57.9 \%$ & $47.9 \%$ \\
\hline Medium & $20.2 \%$ & $25.4 \%$ \\
\hline High & $21.8 \%$ & $26.7 \%(p=0.148)$ \\
\hline \multicolumn{3}{|l|}{ Body Mass Index } \\
\hline Underweight $\left(<18.5 \mathrm{~m}^{2} / \mathrm{kg}\right)$ & $0.5 \%$ & $0.4 \%$ \\
\hline Normal $\left(18.5-25\right.$ m²$\left.^{2} / \mathrm{kg}\right)$ & $26.9 \%$ & $29.5 \%$ \\
\hline Overweight (25-30 m²/kg) & $42.3 \%$ & $48.3 \%$ \\
\hline Obese $\left(\geq 30 \mathrm{~m}^{2} / \mathrm{kg}\right)$ & $30.3 \%$ & $21.8 \%(p=0.207)$ \\
\hline \multicolumn{3}{|l|}{ Chronic Diseases (self-reported) } \\
\hline Cardiovascular & $68.9 \%$ & $61.0 \%(p=0.108)$ \\
\hline Diabetes & $15.5 \%$ & $9.5 \%(p=0.027)$ \\
\hline Pulmonary & $7.7 \%$ & $7.5 \%(p=0.962)$ \\
\hline Allergy & $29.7 \%$ & $22.8 \%(p=0.158)$ \\
\hline Gastrointestinal & $32.0 \%$ & $18.3 \%(p<0.001)$ \\
\hline Neoplasic & $4.0 \%$ & $5.2 \%(p=0.454)$ \\
\hline Mental & $19.3 \%$ & $13.8 \%(p=0.029)$ \\
\hline Neurologic & $3.5 \%$ & $2.9 \%(p=0.602)$ \\
\hline Comorbidity Score & 2.3 & $1.7(p<0.001)$ \\
\hline Longstanding Musculoskeletal Pain & $52.5 \%$ & $34.1 \%(p<0.001)$ \\
\hline SCORE HAQ (0-3 from best to worst) & 0.64 & $0.28(p<0.001)$ \\
\hline SCORE EQ-5D (0-100 from worst to best imaginable health state) & 0.68 & $0.83(p<0.001)$ \\
\hline SF-36 physical function (0-100 from worst to best) & 65.2 & $80.8(p<0.001)$ \\
\hline SF-36 role limitations because of physical health problems & 59.8 & $77.3(p<0.001)$ \\
\hline SF-36 bodily pain & 54.9 & $72.6(p<0.001)$ \\
\hline SF-36 social functioning & 80.3 & $87.8(p<0.001)$ \\
\hline SF-36 general mental health & 58.8 & $69.7(p<0.001)$ \\
\hline SF-36 role limitations because of emotional problems & 71.2 & $85.3(p<0.001)$ \\
\hline SF-36 vitality & 51.4 & $61.9(p<0.001)$ \\
\hline SF-36 general health perceptions & 47.8 & $56.6(p<0.001)$ \\
\hline
\end{tabular}

All results were computed as weighted proportions to keep in account the sampling design of the survey

${ }^{*}$ All $p$ values: OA versus non-OA. OA, Osteoarthritis; HAQ, Health Assessment Questionnaire; EQ-5D, European Quality of Life index; SF-36, Short-Form Health Survey

\section{Association between $O A$ and early exit from work}

OA is associated with early exit from work (OR: 1.85; 95\%CI: $1.27-2.69 ; p=0.001$ ), but not with official early retirement (OR: 1.43 ; 95\%CI: $0.96-2.12 ; p=0.08$ ). Knee location of $\mathrm{OA}$ is strongly associated with early exit from work (OR: 2.25 ; 95\%CI: $1.42-3.59 ; p=0.001$. Appendix
2), while no significant association was observed for hand OA (OR: 1.17; 95\%CI: 0.76-1.80; $p=0.477$ ) or hip OA (OR: $1.04 ; 95 \%$ CI: $0.36-2.99 ; p=0.938$ ). As mentioned above, unemployment seems to be a major channel of exit from work for patients with OA (OR: 1.97; 95\%CI: $1.27-3.06 ; p=0.002$ ), especially for knee OA 


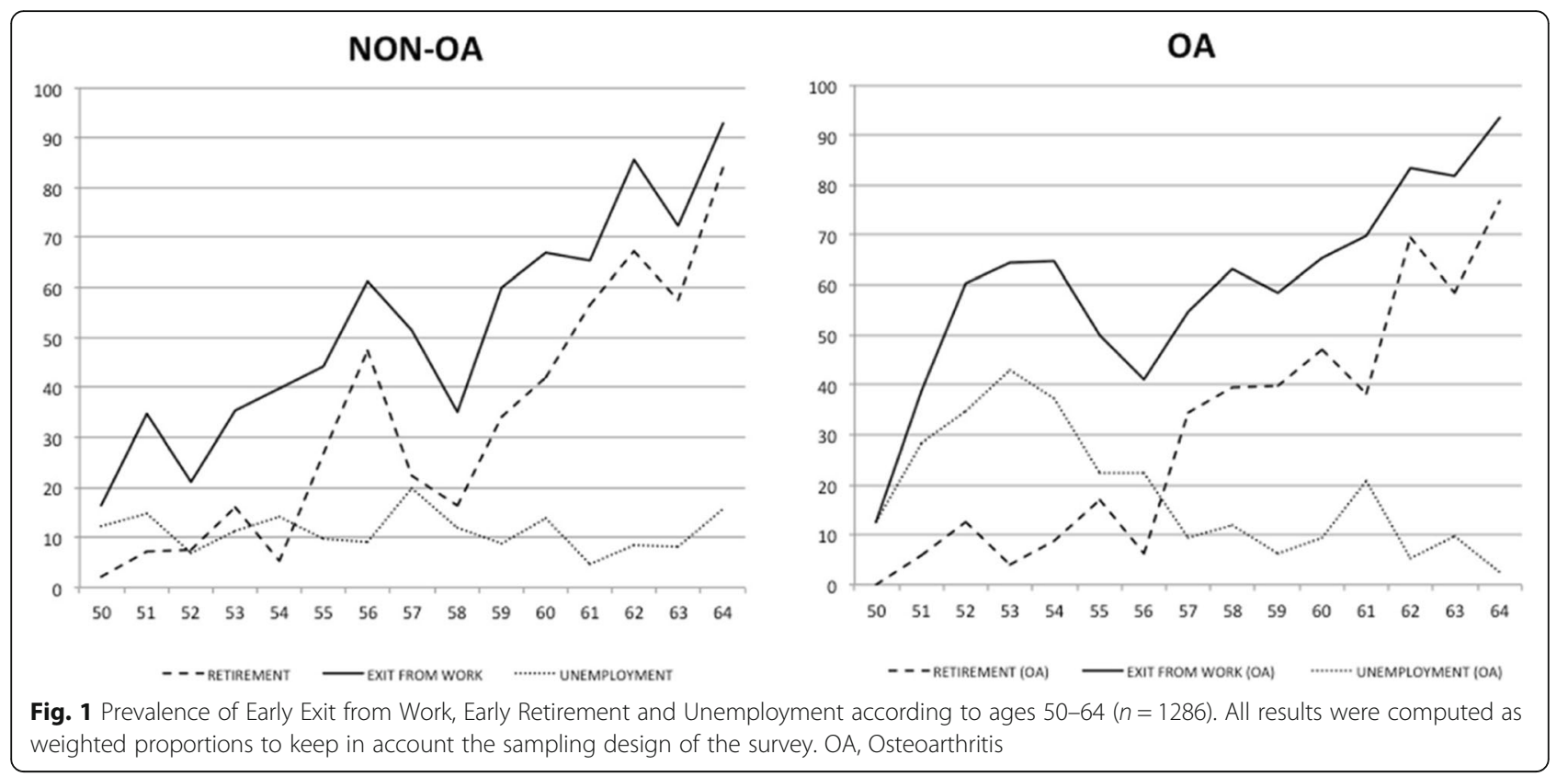

(OR: 2.68; 95\%CI: 1.58-4.53; $p<0.001$. Table 2), and for the youngest (50-57) from the sample (OR: 3.47; 95\%CI: $1.88-6.41 ; p<0.001)$.

\section{Pain and disability}

Pain plays a key role in the risk of workforce withdrawal. A strong association was seen between pain interference and premature work loss, especially within the knee OA population (OR: 1.52; 95\%CI: 1 . $16-1.99 ; p=0.002)$. Those who scored worse in pain interference were more often out-of-work (Fig. 2). In fact, not only was the OA population more likely to score worse $(p=0.02)$ in this parameter, but also the aforementioned association between knee OA and exit from work becomes non-significant if only the subset of population with low pain interference is analysed (i.e. "not at all" "to a little bit" pain interference. OR: 1.52; 95\%CI: 0.95-2.44; $p=0.08)$.

Furthermore, knee OA patients with the highest levels of disability measured by HAQ (scores $\geq 2$ ), are at the greatest risk of early exit from work $(80.7 \%$ vs. $67.4 \%$ for all knee OA population and $51.2 \%$ for those with HAQ scores $\geq 2$ but without knee OA). We estimated an almost linear relationship between levels of

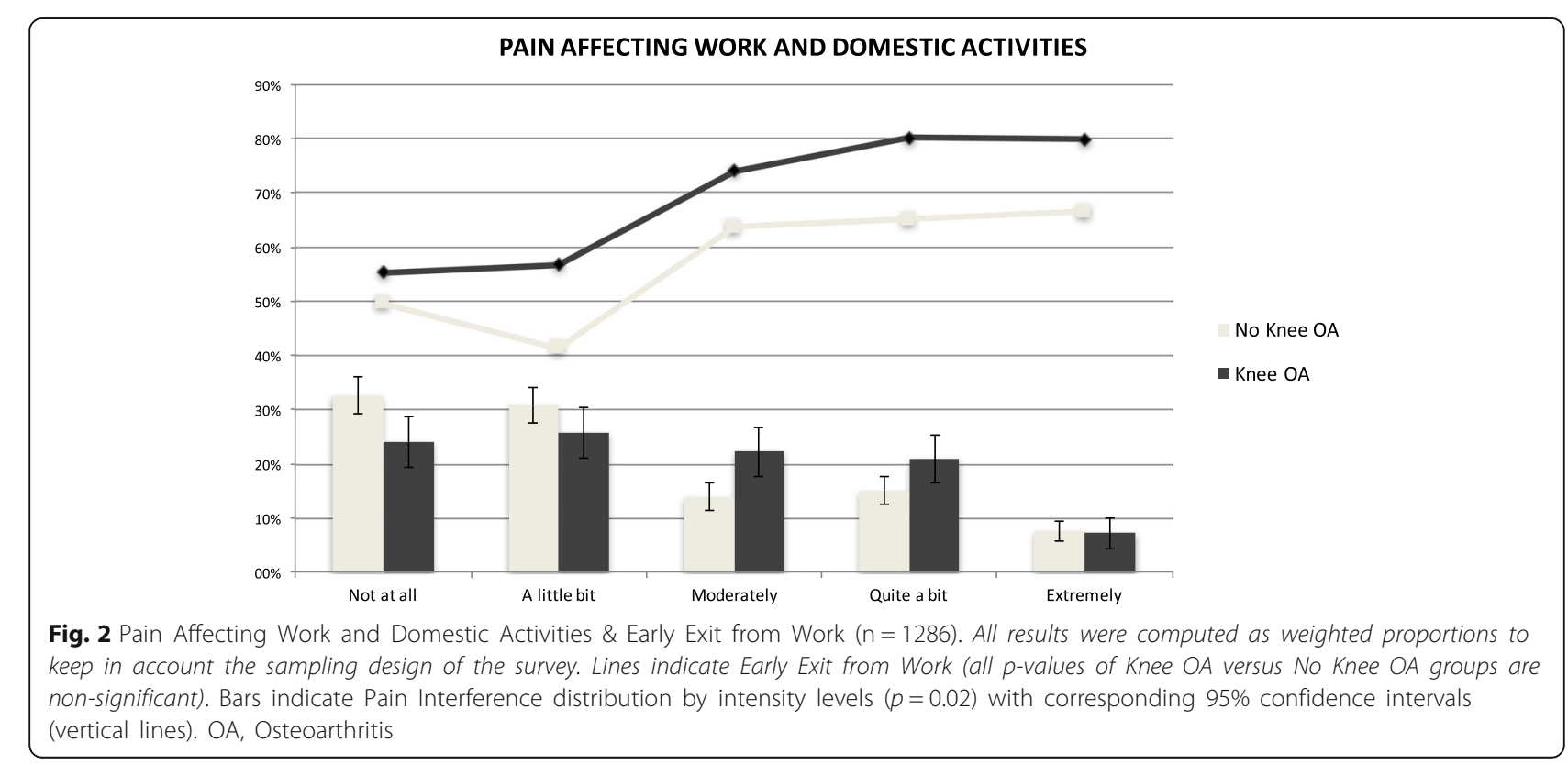


disability and the probability of early exit from paid employment, with its y-intercept increasing with the presence of knee OA (Appendix 3). Similarly to what was observed with pain, the association between knee $\mathrm{OA}$ and exit from work becomes non-significant if only the subset of population with less disability is analysed (i.e. HAQ scores below the average of the population [0.38]. OR: 0.74; CI: $0.28-1.99 ; p=0.552$ ).

\section{Economic burden}

The estimated annual indirect cost due to premature exit from work attributable to OA was $€ 656$ million (€384 per capita; €1294 per OA patient and $€ 2095$ per OA patient out-of-work). Females contributed with $61.6 \%$ of these costs (€404 million), but mean per capita indirect costs were greater for $\mathrm{OA}$ males (cost per OA male patient: $€ 1795$ vs. $€ 1102$ for females; cost per OA male patient out-of-work: $€ 2776$ vs. $€ 1817$ for females Fig. 3).

\section{Discussion}

In this study, using the first nationwide epidemiological population-based survey that evaluated rheumatic diseases in Portugal, we found an association between clinically confirmed OA and early exit from paid employment. However, this relationship was only found for the knee OA (not for hip or hand OA). We also estimated that OA might have led to annual indirect costs amounting to approximately $0.4 \%$ of the 2013 national Gross Domestic Product (GDP). Women contributed with $61.6 \%$ of this productivity loss, whilst OA men have higher mean per capita indirect costs given the higher average unit values of production associated with male gender [31].

As expected [1], OA patients are mostly ageing females when compared with the non-OA population. They have lower levels of education, lower household income, poorer self-reported quality of life, and a higher

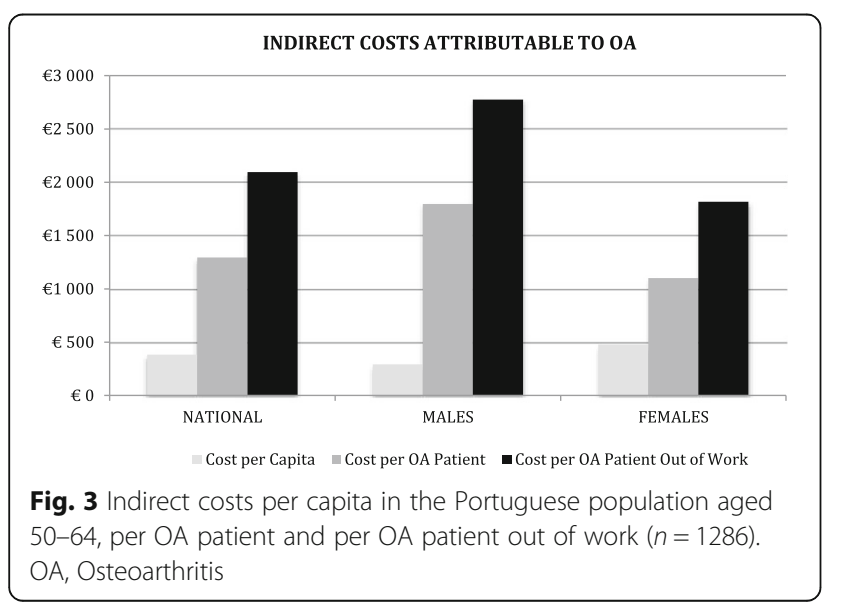

number of comorbidities. These characteristics may themselves influence labour force participation. In fact, we observed an association between premature work loss and lower levels of education, marital status (married or widowed), neurological diseases, and lower household income. Nevertheless, the association we found between clinically confirmed $\mathrm{OA}$ and premature work withdrawal is robust and independent of other influencing factors, which is consistent with previously published data [32-34].

OA generates disabling pain, which might push patients to leave work prematurely [14]. We captured pain through alternative measures (i.e. pain interference, bodily pain item from the SF-36 questionnaire, and selfreported longstanding musculoskeletal pain) and, as expected, OA patients consistently report more pain than others without the condition. In addition, we observed a relation between pain and withdrawal from employment. This is consistent with the literature $[32,35,36]$. For instance, Dibonaventura et al., using data from the US National Health and Wellness Survey, have shown that individuals with OA pain were less likely to be employed relative to workers without OA pain [35]. We also detected that OA patients with higher levels of disability, measured by high scores of $\mathrm{HAQ}$, were at the highest risk of early exit from work. This also aligns with earlier research $[37,38]$ and with the etiological model adopted, which assumes that OA generates pain, impairment, and disability that may ultimately lead to work withdrawal. Thus, we confirmed in our research and study population that pain and disability are key factors for job loss driven by OA.

Interestingly, we did not find a statistical association between $\mathrm{OA}$ and official early retirement (regardless of anatomic location). OA seems instead to drive the labour force out of paid employment mainly through unemployment. This is particularly evident in the earlier ages. Thereafter unemployment is overtaken by early retirement when patients with OA get closer to the official retirement age. We did not find the same interplay between age-specific frequencies of retirement and unemployment in the non-OA population. Thus, unemployment appears to be the predominant first step to irreversible out-of-work state in OA patients, although likely not being fully converted into official early retirement, given the lack of association between early retirement and OA (in Portugal, under some circumstances, unemployment benefits may be converted into the old-age pension before reaching the statutory retirement age).

It would be valuable to further explore if this occurs because labour market policies are restricting early retirement in this sort of patients (e.g. formal rejection of early retirement applications to Social 
Security from employees with OA) or if other reasons are taking the lead instead. This finding highlights the need to target research and integration-oriented policies toward unemployment generated by OA. More knowledge in this area may produce employment gains since premature retirement restriction policies by themselves are insufficient to mitigate the job losses, as alternative routes may take place as seen herein in the OA case. Although unemployment benefits may be time limited, from the societal perspective these pathways of early exit from work embody the same economic burden (i.e. identical productivity losses), and therefore strategies that simply push individuals from one route to another are truly not socially efficient.

In this nationwide study, we estimated a substantial economic burden following early exit from work attributable to OA, equivalent to an indirect annual cost of $€ 656$ million euros (€2061 per patient). Earlier research in other countries has measured different yearly indirect costs of OA per patient [39-46]. Comparing results of cost-of-illness studies is hampered by discrepancies across study designs, case definition, methodological choices, wage levels, and sources of data used [47]. Additionally, these cost results vary with time and geography. However, there are some common take-away messages: First, the economic burden of osteoarthritis is considerable and closely related to its high prevalence. Second, indirect costs are likely to surpass other per patient costs (e.g. drug and other medical costs) $[42,48,49]$. Third, these costs are also likely to exceed those from other chronic disabling conditions. For example, Schofield et al. measured annual losses of arthritis through early retirement (approximately $0.7 \%$ of GDP) [50] superior to other pathologies, such as cardiovascular disease [51], diabetes [52], and mental disorders [53].

This study has several limitations that must be taken into account when interpreting its results. First, it may be limited by the cross-sectional design, which does not allow for an evaluation of the temporal relationship between onset of OA and time of exit from paid employment, which would help in establishing a cause-effect relationship. Lack of available national longitudinal data made this limitation impossible to overcome. Nevertheless, onset of OA is likely to start before premature exit from paid employment and reverse causality is unlikely (i.e. early exit from work as a risk factor to OA onset). Second, wages were estimated through official statistics based on gender, region, and age. Necessarily, this methodology is a rough estimate of the individual unit values of production. In particular, OA patients are likely associated with lower incomes. Still, given the information available, it is the best feasible method. Third, due to the cross-sectional design, our results are rightcensored, leading to likely underestimation of the results (i.e. further exit from work is more probable to occur than return to work within the sample until all participants reach the official retirement age). Finally, not all potential hidden confounding factors could be addressed. However, we do not consider our analysis to be overly influenced by this limitation given the richness of the EpiReumaPt dataset and the large number of control variables thus afforded.

This study has several strengths as well. It is based on the largest population-based study about rheumatic diseases ever performed in Portugal (i.e. high external validity). It uses confirmed diagnosis of OA done by rheumatologists (i.e. very strict and controlled case definition). To our knowledge, this must be amongst the few studies focusing on indirect costs of OA based on such a representative sample specifically dedicated to rheumatic and musculoskeletal conditions, a sample that is likely to accurately reflect this particular type of economic impact on society. It will certainly facilitate future research on the cost-effectiveness of interventions targeting reduced work ability due to OA.

Unquestionably, this issue deserves further attention. Recently, access to early retirement was restricted in some European countries that are still lacking in integration policies such as vocational rehabilitation programmes [54]. Since OA is highly disabling and prevalent, especially at ages near the statutory retirement age, it might well be an ideal area in which public policies might strive for a better balance between restricting early retirement and integration policies. Moreover, OA is a musculoskeletal disease for which the etiological model (from the onset of symptoms/pain until work withdrawal) may be further understood and subsequently disrupted by effective health interventions.

\section{Conclusions}

This population-based study unveils the impact of the association between OA and early exit from paid employment. It describes the high economic burden underlying this association. The findings justify giving more attention to $\mathrm{OA}$ when discussing policies facing the ageing of higher income countries. The depreciation in the stock of human capital due to $\mathrm{OA}$ is already extensive, and given the demographic and epidemiological trends, it may even worsen if nothing is done. This research should provide important evidence for decision makers to prioritize investments in health and policies targeting patients with OA. 


\section{Appendices}

\section{Appendix 1}

Table 3 Summary of average unit values of production by gender, age and geographic region (2013)

\begin{tabular}{|c|c|c|c|c|c|c|}
\hline Age & National & North & Center & Lisbon & Alentejo & Algarve \\
\hline \multicolumn{7}{|l|}{ MEN } \\
\hline 50 & $€ 22,868$ & $€ 21,271$ & $€ 21,091$ & $€ 32,376$ & $€ 21,147$ & $€ 19,808$ \\
\hline 51 & $€ 23,875$ & $€ 21,066$ & $€ 20,753$ & $€ 32,081$ & $€ 21,659$ & $€ 18,518$ \\
\hline 52 & $€ 24,609$ & $€ 21,357$ & $€ 20,290$ & $€ 31,991$ & $€ 22,772$ & $€ 19,523$ \\
\hline 53 & $€ 24,688$ & $€ 21,497$ & $€ 20,834$ & $€ 32,895$ & $€ 22,182$ & $€ 18,722$ \\
\hline 54 & $€ 25,831$ & $€ 21,942$ & $€ 20,475$ & $€ 31,422$ & $€ 24,079$ & $€ 19,314$ \\
\hline 55 & $€ 25,624$ & $€ 22,005$ & $€ 21,086$ & $€ 32,877$ & $€ 23,712$ & $€ 20,063$ \\
\hline 56 & $€ 25,185$ & $€ 22,005$ & $€ 21,065$ & $€ 33,006$ & $€ 24,686$ & $€ 18,943$ \\
\hline 57 & $€ 25,813$ & $€ 22,665$ & $€ 20,187$ & $€ 33,248$ & $€ 23,917$ & $€ 20,398$ \\
\hline 58 & $€ 23,696$ & $€ 22,757$ & $€ 20,719$ & $€ 34,349$ & $€ 24,228$ & $€ 18,808$ \\
\hline 59 & $€ 25,881$ & $€ 23,593$ & $€ 21,222$ & $€ 34,765$ & $€ 25,096$ & $€ 20,406$ \\
\hline 60 & $€ 23,843$ & $€ 21,586$ & $€ 20,037$ & $€ 32,585$ & $€ 24,078$ & $€ 19,509$ \\
\hline 61 & $€ 26,350$ & $€ 22,616$ & $€ 21,393$ & $€ 36,334$ & $€ 22,330$ & $€ 19,943$ \\
\hline 62 & $€ 25,966$ & $€ 24,180$ & $€ 20,432$ & $€ 34,934$ & $€ 25,275$ & $€ 18,210$ \\
\hline 63 & $€ 24,645$ & $€ 23,053$ & $€ 19,851$ & $€ 33,056$ & $€ 25,360$ & $€ 17,408$ \\
\hline 64 & $€ 24,490$ & $€ 24,474$ & $€ 20,181$ & $€ 34,764$ & $€ 28,163$ & $€ 17,266$ \\
\hline Average (50-64) & $€ 24,891$ & $€ 22,404$ & $€ 20,641$ & $€ 33,379$ & $€ 23,912$ & $€ 19,123$ \\
\hline \multicolumn{7}{|l|}{ WOMEN } \\
\hline 50 & $€ 16,290$ & $€ 14,524$ & $€ 13,384$ & $€ 20,811$ & $€ 13,740$ & $€ 15,466$ \\
\hline 51 & $€ 15,880$ & $€ 14,864$ & $€ 13,451$ & $€ 20,522$ & $€ 13,811$ & $€ 15,637$ \\
\hline 52 & $€ 16,709$ & $€ 15,202$ & $€ 13,291$ & $€ 20,965$ & $€ 14,281$ & $€ 15,595$ \\
\hline 53 & $€ 16,165$ & $€ 15,006$ & $€ 13,067$ & $€ 21,020$ & $€ 14,068$ & $€ 14,931$ \\
\hline 54 & $€ 17,526$ & $€ 15,250$ & $€ 13,158$ & $€ 21,075$ & $€ 13,612$ & $€ 14,653$ \\
\hline 55 & $€ 16,504$ & $€ 15,379$ & $€ 13,459$ & $€ 20,312$ & $€ 13,731$ & $€ 15,434$ \\
\hline 56 & $€ 15,437$ & $€ 15,251$ & $€ 13,343$ & $€ 21,297$ & $€ 14,298$ & $€ 15,507$ \\
\hline 57 & $€ 15,557$ & $€ 15,313$ & $€ 12,612$ & $€ 20,181$ & $€ 14,629$ & $€ 15,402$ \\
\hline 58 & $€ 15,359$ & $€ 15,205$ & $€ 13,018$ & $€ 19,968$ & $€ 13,632$ & $€ 14,444$ \\
\hline 59 & $€ 16,881$ & $€ 16,023$ & $€ 14,525$ & $€ 19,495$ & $€ 13,140$ & $€ 15,262$ \\
\hline 60 & $€ 15,727$ & $€ 15,726$ & $€ 13,192$ & $€ 19,362$ & $€ 13,180$ & $€ 15,151$ \\
\hline 61 & $€ 16,103$ & $€ 15,792$ & $€ 12,819$ & $€ 19,901$ & $€ 13,359$ & $€ 13,546$ \\
\hline 62 & $€ 15,954$ & $€ 15,860$ & $€ 13,088$ & $€ 20,745$ & $€ 13,340$ & $€ 14,257$ \\
\hline 63 & $€ 15,629$ & $€ 15,452$ & $€ 13,850$ & $€ 18,797$ & $€ 13,298$ & $€ 16,413$ \\
\hline 64 & $€ 15,460$ & $€ 15,489$ & $€ 13,070$ & $€ 17,956$ & $€ 13,426$ & $€ 14,059$ \\
\hline Average (50-64) & $€ 16,079$ & $€ 15,356$ & $€ 13,288$ & $€ 20,160$ & $€ 13,703$ & $€ 15,050$ \\
\hline NATIONAL & $€ 20,255$ & & & & & \\
\hline
\end{tabular}

Note: National values are weighted averages according with each age, sex and region population size 


\section{Appendix 2}

Table 4 Logistic regression analysis by type of early exit from paid employment

\begin{tabular}{|c|c|c|c|c|c|c|}
\hline & \multicolumn{2}{|l|}{ Unemployment } & \multicolumn{2}{|l|}{ Early Retirement } & \multicolumn{2}{|c|}{ Early Exit From Paid Employment } \\
\hline & $\begin{array}{l}\text { Univariable OR } \\
(95 \% \text { CI) }\end{array}$ & $\begin{array}{l}\text { Multivariable OR } \\
(95 \% \mathrm{Cl})^{a}\end{array}$ & $\begin{array}{l}\text { Univariable OR } \\
(95 \% \mathrm{Cl})\end{array}$ & $\begin{array}{l}\text { Multivariable OR } \\
\left(95 \%()^{a}\right.\end{array}$ & $\begin{array}{l}\text { Univariable OR } \\
(95 \% \text { CI) }\end{array}$ & $\begin{array}{l}\text { Multivariable OR } \\
\left(95 \%()^{a}\right.\end{array}$ \\
\hline Knee Osteoarthritis & $1.97^{*}(1.25-3.10)$ & $2.68^{*}(1.58-4.53)$ & $1.37(0.90-2.08)$ & - & $2.22^{*}(1.49-3.29)$ & $2.25^{*}(1.42-3.59)$ \\
\hline Age & $0.99 *(0.97-1.00)$ & $0.98^{*}(0.97-1.00)$ & $1.03^{*}(1.01-1.04)$ & $1.03^{*}(1.01-1.04)$ & $1.01(1.00-1.03)$ & $1.01^{*}(1.00-1.03)$ \\
\hline Gender (Female) & $1.31(0.83-2.09)$ & $1.06(0.61-1.84)$ & $0.75(0.47-1.18)$ & $0.64(0.41-1.00)$ & $1.27(0.80-2.00)$ & $1.23(0.79-1.93)$ \\
\hline \multicolumn{7}{|c|}{ Educational level (Ref: Primary or less) } \\
\hline Medium & $0.89(0.51-1.56)$ & - & $0.47^{*}(0.26-0.84)$ & $0.46^{*}(0.23-0.92)$ & $0.41^{*}(0.22-0.74)$ & $0.31^{*}(0.18-0.55)$ \\
\hline High & $0.77(0.44-1.34)$ & - & $0.46^{*}(0.26-0.80)$ & $0.62(0.36-1.06)$ & $0.29^{*}(0.17-0.49)$ & $0.49^{*}(0.27-0.89)$ \\
\hline \multicolumn{7}{|l|}{ Marital Status (Ref: Single) } \\
\hline Married/Consensual Union & $0.85(0.36-1.99)$ & - & $4.38^{*}(1.81-10.57)$ & $4.21^{*}(1.62-10.92)$ & $3.11^{*}(1.30-7.43)$ & $5.28^{*}(2.24-12.45)$ \\
\hline Divorced & $0.97(0.36-2.57)$ & - & $2.89(0.97-8.63)$ & $2.99(0.97-9.22)$ & $1.77(0.64-4.87)$ & $1.78(0.69-4.58)$ \\
\hline Widowed & $0.41(0.13-1.29)$ & - & $6.14^{*}(2.23-16.93)$ & $6.08^{*}(2.00-18.48)$ & $3.93^{*}(1.50-10.29)$ & $4.04^{*}(1.34-12.17)$ \\
\hline \multicolumn{7}{|l|}{ Chronic Diseases } \\
\hline Cardiovascular & $0.88(0.55-1.42)$ & - & $0.97(0.58-1.62)$ & - & $1.04(0.64-1.68)$ & - \\
\hline Diabetes & $0.87(0.47-1.61)$ & & $2.25^{*}(1.30-3.89)$ & $1.92^{*}(1.09-3.41)$ & $2.78^{*}(1.67-4.65)$ & - \\
\hline Pulmonary & $0.98(0.43-2.24)$ & - & $2.08(0.83-5.21)$ & - & $2.08(0.84-5.15)$ & - \\
\hline Allergy & $0.86(0.51-1.44)$ & - & $0.70(0.41-1.20)$ & - & $0.76(0.43-1.33)$ & - \\
\hline Gastrointestinal & $1.02(0.63-1.66)$ & - & $1.40(0.89-2.23)$ & - & $1.45(0.91-2.31)$ & - \\
\hline Neoplasic & $1.27(0.50-3.26)$ & - & $1.61(0.70-3.70)$ & - & $1.51^{*}(0.62-3.65)$ & \\
\hline Mental & $1.04(0.64-1.70)$ & - & $0.82(0.54-1.23)$ & - & $1.34(0.91-1.99)$ & - \\
\hline Neurologic & $0.50(0.15-1.59)$ & - & $4.83^{*}(2.19-10.66)$ & $5.00^{*}(1.95-12.83)$ & $4.17^{*}(1.83-9.50)$ & $4.58^{*}(1.40-15.00)$ \\
\hline \multicolumn{7}{|l|}{ Household Income (Ref: $\leq € 500$ ) } \\
\hline$>€ 500$ and $\leq € 1000$ & $0.31^{*}(0.18-0.55)$ & $0.36^{*}(0.20-0.64)$ & $0.84(0.43-1.62)$ & - & $0.43^{*}(0.23-0.80)$ & $0.40^{*}(0.23-0.69)$ \\
\hline$>€ 1000$ and $\leq € 2000$ & $0.10^{*}(0.04-0.24)$ & $0.12^{*}(0.05-0.28)$ & $0.98(0.45-2.12)$ & - & $0.26^{*}(0.12-0.54)$ & $0.25^{*}(0.12-0.53)$ \\
\hline$>€ 2000$ & $0.15^{*}(0.06-0.43)$ & $0.18^{*}(0.06-0.50)$ & $0.79(0.34-1.81)$ & - & $0.22^{*}(0.10-0.49)$ & $0.25^{*}(0.10-0.65)$ \\
\hline Regional Controls & & YES & & YES & & YES \\
\hline
\end{tabular}

OR odds ratio, $\mathrm{Cl}$ confidence interval, ${ }^{*} p<0.05$

a- All multivariable models were adjusted for age, gender, geographic region (7 main regions: North, Center, Lisbon region, Alentejo, Algarve, Azores and Madeira), marital status, education level, household income, body mass index and chronic diseases. Cofactors were excluded in the stepwise method if $p>0.05$ (except for age and gender) 


\section{Appendix 3}
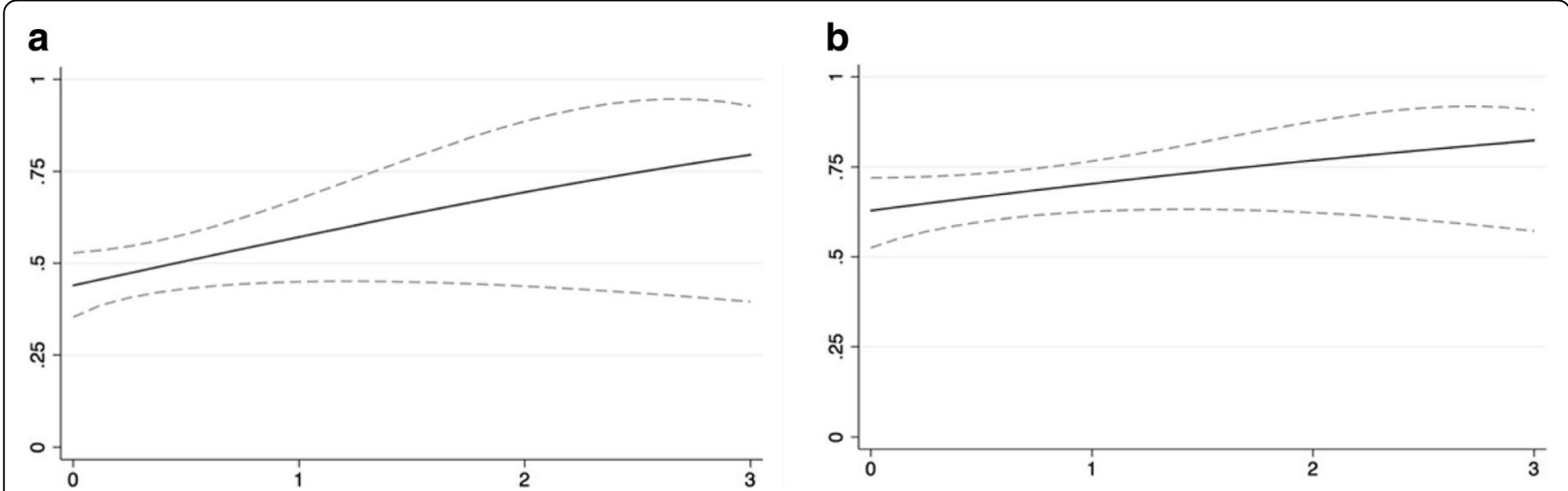

Fig. 4 Relationship between disability levels and probability of early exit from work (by presence of knee OA). a Without knee OA; b With knee OA. $\mathrm{OA}$, osteoarthritis; $\mathrm{HAQ}$, Health Assessment Questionnaire. Median bands are depicted in solid lines, while the confidence interval consists of the space between the two dashed lines

\section{Abbreviations}

ACR: American College of Rheumatology; BMI: Body Mass Index; EQ5D: European Quality of Life questionnaire; GDP: Gross Domestic Product; HAQ: Health Assessment Questionnaire; OA: Osteoarthritis; OR: Odds Ratio; PAF: Population Attributable Fractions; SF-36: 36-Item Short Form Survey

\section{Acknowledgements}

We acknowledge the invaluable help from all rheumatologists and investigators who contributed to the EpiReumaPt study. We would also like to acknowledge the EpiReumaPt external consultants: João Eurico da Fonseca, MD PhD; Loreto Carmona, MD PhD; Henrique de Barros, MD PhD; and José António Pereira da Silva, MD PhD.

\section{Funding}

None.

\section{Availability of data and materials}

The datasets used and/or analysed during the current study are available from the corresponding author on reasonable request.

\section{Authors' contributions}

$\mathrm{PL}, \mathrm{HC}, \mathrm{AMR}, \mathrm{ME}$ and JCB contributed substantially to the dataset of the EpiReumaPt study. PL and MG developed this analysis design. PL, HC and MG were responsible for data analysis and interpretation. All authors read and approved the final manuscript.

\section{Ethics approval and consent to participate}

The EpiReumaPt study was performed according to the principles established by the 1964 Helsinki declaration and its later amendments and according to Portuguese law. EpiReumaPt was reviewed and approved by competent Portuguese authorities: NOVA Medical School Ethics Committee and National Committee for Data Protection. The study was also reviewed and approved by the Ethical Committees of Regional Health Authorities. Further details of ethical issues of EpiReumaPt have been described elsewhere [55].

Written informed consent was obtained from all individual participants included in the study [56].

\section{Consent for publication}

Not applicable.

\section{Competing interests}

The authors declare that they have no competing interests.

\section{Publisher's Note}

Springer Nature remains neutral with regard to jurisdictional claims in published maps and institutional affiliations.

\section{Author details}

${ }^{1}$ Faculdade de Medicina da Universidade de Lisboa, Lisbon Academic Medical Center, Lisbon, Portugal. ${ }^{2}$ Centro de Investigação em Saúde Pública, Escola Nacional de Saúde Pública, Lisbon, Portugal. ${ }^{3}$ EpiReumaPt Study Group, Sociedade Portuguesa de Reumatologia, Lisbon, Portugal. ${ }^{4}$ Chronic Diseases Research Center (CEDOC), NOVA Medical School, Universidade Nova de Lisboa (NMS/UNL), Lisbon, Portugal. ${ }^{5}$ Catolica Lisbon School of Business and Economics, Lisbon, Portugal. ${ }^{6}$ Rheumatology Department, Hospital Egas Moniz, Centro Hospitalar Lisboa Ocidental (CHLO- E.P.E.), Lisbon, Portugal.

Received: 30 January 2017 Accepted: 26 March 2018 Published online: 11 April 2018

\section{References}

1. Plotnikoff R, Karunamuni N, Lytvyak E, Penfold C, Schopflocher D, Imayama I, Johnson ST, Raine K. Osteoarthritis prevalence and modifiable factors: a population study. BMC Public Health. 2015:15:1195.

2. Woolf $A D$, Pfleger B. Burden of major musculoskeletal conditions. Bull World Health Organ. 2003;81(9):646-56.

3. Arden N, Nevitt MC. Osteoarthritis: epidemiology. Best Pract Res Clin Rheumatol. 2006:20:3-25.

4. Jordan JM, Luta G, Renner JB, et al. Self-reported functional status in osteoarthritis of the knee in a rural southern community: the role of sociodemographic factors, obesity, and knee pain. Arthritis Care Res. 1996;9:273-8

5. IImarinen JE. Aging workers. Occup Environ Med. 2001;58:546e52.

6. Laires PA, Gouveia M. Association of rheumatic diseases with early exit from paid employment in Portugal. Rheumatol Int. 2014:34(4):491-502.

7. Dwyer DS, Mitchell OS. Health problems as determinants of retirement: are self-rated measures endogenous? J Health Econ. 1999;18(2):173-93.

8. Alavinia SM, Burdorf A. Unemployment and retirement and ill-health: a cross- sectional analysis across European countries. Int Arch Occup Environ Health. 2008:82:39e45.

9. Cai L, Kalb G. Health status and labour force participation: evidence from Australia. Health Econ. 2006:15:241e61.

10. Stattin M. Retirement on grounds of ill health. Occup Environ Med. 2005:62:135e40

11. Van den Berg T, Schuring M, Avendano M, Mackenbach J, Burdorf A. The impact of ill health on exit from paid employment in Europe among older workers. Occup Environ Med. 2010;67(12):845-52. 
12. Schuring $M$, Burdorf $L$, Kunst $A$, et al. The effects of ill health on entering and maintaining paid employment: evidence in European countries. J Epidemiol Community Health. 2007;61:597e604.

13. Rice NE, Lang I, Henley W, Melzer D. Common health predictors of early retirement: findings from the English Longitudinal Study of Ageing. Age Ageing. 2011;40(1):54-61.

14. Bieleman HJ, Bierma-Zeinstra SM, Oosterveld FG, Reneman MF, Verhagen AP, Groothoff JW. The effect of osteoarthritis of the hip or knee on work participation. J Rheumatol. 2011;38(9):1835-43.

15. Bieleman HJ. Work loss in osteoarthritis. Rheumatology (Oxford). 2014;53(3): 387-8.

16. Branco JC, et al. Prevalence of Rheumatic and Musculoskeletal Diseases and Their Impact on Health-Related Quality of Life, Physical Function and Mental Health in Portugal: Results from EpiReumaPt- a National Health Survey. RMD Open. 2016:2(1):e000166.

17. Rodrigues AM, Gouveia N, Costa LP, Eusébio M, Ramiro S, Machado P, Mourão AF, Silva I, Laires P, Sepriano A, Araújo F, Coelho PS, Gonçalves S, Zhao A, Fonseca JE, Almeida JM, Tavares V, da Silva JA, Barros H, Cerol J, Mendes J, Carmona L, Canhão H, Branco JC. EpiReumaPt- the study of Rheumatic and Musculoskeletal diseases in Portugal: A detailed view of the methodology. Acta Reumatol Port. 2015:40(2):110-24

18. Altman R, Asch E, Bloch D, et al. Development of criteria for the classification and reporting of osteoarthritis. Classification of osteoarthritis of the knee. Diagnostic and Therapeutic Criteria Committee of the American Rheumatism Association. Arthritis Rheum. 1986:29(8):1039-49.

19. Altman R, Alarcon G, Appelrouth $D$, et al. The American College of Rheumatology criteria for the classification and reporting of osteoarthritis of the hip. Arthritis Rheum. 1991;34(5):505-14.

20. Altman R, Alarcon G, Appelrouth D, et al. The American College of Rheumatology criteria for the classification and reporting of osteoarthritis of the hand. Arthritis Rheum. 1990;33(11):1601-10.

21. Ware JE, Sherbourne CD. The MOS 36-Item Short-Form Health Survey (SF-36). Conceptual framework and item selection. Med Care. 1992;30:473-83.

22. Ferreira PL. Criação da versão portuguesa do MOS SF-36. Parte I Adaptação cultural e linguística. Acta Medica Port. 2000;13(1-2):55-66.

23. Ferreira LN, Ferreira PL, Pereira LN, Oppe M. EQ-5D Portuguese population norms. Quality of life research : an international journal of quality of life aspects of treatment, care and rehabilitation. 2014;23(2):425-30.

24. Ferreira LN, Ferreira PL, Pereira LN, Oppe M. The valuation of the EQ-5D in Portugal. Qual Life Res Int J Qual Life Asp Treat Care Rehab. 2014;23(2):413-23.

25. Fries JF, Spitz P, Kraines RG, Holman HR. Measurement of patient outcome in arthritis. Arthritis Rheum. 1980;23(2):137-45.

26. Gouveia M, Augusto M. Custos indirectos da dor crónica em Portugal. Rev Port Saúde Pública. 2011;29(2):99-106.

27. Becker G. Human capital. New York: National Bureau of Economic Research; 1975.

28. Personnel Records 2013 Ministry of Solidarity and Social Security / Office for Strategy and Planning GEP/MSSS (Quadros de Pessoal 2013- Ministério da Solidariedade e da Segurança Social / Gabinete de Estratégia e Planeamento). [Portuguese].

29. Gunasekara Fl, Carter K, Blakely T. Glossary for econometrics and epidemiology. J Epidemiol Community Health. 2008;62:858-61.

30. Rothman KJ, Greenland S, editors. Modern Epidemiology. 2nd ed. Philadelphia: Lippincott-Rave; 1998

31. Cardoso AR, Guimarães $P$, Portugal $P$, et al. The sources of the gender wage gap. Banco de Portugal Economic Studies Vol. 2016;2(N2):47-66: https://www.bportugal.pt/sites/default/files/anexos/pdf-boletim/reev2n2_e.pdf

32. Wilkie R, Phillipson C, Hay E, Pransky G. Frequency and predictors of premature work loss in primary care consulters for osteoarthritis: prospective cohort study. Rheumatology (Oxford). 2014;53(3):459-64

33. Pit SW, Shrestha R, Schofield D, Passey M. Partial and complete retirement due to ill-health among mature age Australians. Public Health. 2013;127(6):561-71.

34. Gignac M, Cao X, Lacaille D, Anis A, Badley EM. Arthritis-related work transitions: a prospective analysis of reported productivity losses, work changes, and leaving the labor force. Arthritis \& Rheumatism (Arthritis Care \& Research). 2008;59(12):1805-13.

35. Dibonaventura M, Gupta S, McDonald M, Sadosky A. Evaluating the health and economic impact of osteoarthritis pain in the workforce: results from the National Health and Wellness Survey. BMC Musculoskelet Disord. 2011;12:83.
36. Azevedo LF, Costa-Pereira A, Mendonça L, Dias CC, Castro-Lopes JM. The economic impact of chronic pain: a nationwide population-based cost-ofillness study in Portugal. Eur J Health Econ. 2016;17(1):87-98.

37. Saastamoinen $\mathrm{P}$, Laaksonen $\mathrm{M}$, Kääriä SM, Lallukka T, Leino-Arjas $\mathrm{P}$, Rahkonen O, Lahelma E. Pain and disability retirement: a prospective cohort study. Pain. 2012;153(3):526-31.

38. Dibonaventura MD, Gupta S, McDonald M, Sadosky A, Pettitt D, Silverman S. Impact of self-rated osteoarthritis severity in an employed population: crosssectional analysis of data from the national health and wellness survey. Health Qual Life Outcomes. 2012;10:30.

39. Maetzel A, Li LC, Pencharz J, Tomlinson G, Bombardier C. The economic burden associated with osteoarthritis, rheumatoid arthritis, and hypertension: a comparative study. Ann Rheum Dis. 2004;63:395-401.

40. Gabriel SE, Crowson CS, Campion ME, O'Fallon WM. Indirect and nonmedical costs among people with rheumatoid arthritis and osteoarthritis compared with nonarthritic controls. J Rheumatol. 1997;24:43-8.

41. Li X, Gignac MA, Anis AH. The indirect costs of arthritis resulting from unemployment, reduced performance, and occupational changes while at work. Med Care. 2006;44:304-10.

42. Gupta S, Hawker GA, Laporte A, Croxford R, Coyte PC. The economic burden of disabling hip and knee osteoarthritis $(\mathrm{OA})$ from the perspective of individuals living with this condition. Rheumatology (Oxford). 2005:44:1531-7.

43. Woo J, Lau E, Lau CS, Lee P, Zhang J, Kwok T, et al. Socio- economic impact of osteoarthritis in Hong Kong: utilization of health and social services, and direct and indirect costs. Arthritis Rheum. 2003;49:526-34.

44. Leardini G, Salaffi F, Caporali R, Canesi B, Rovati L, Montanelli R. Direct and indirect costs of osteoarthritis of the knee. Clin Exp Rheumatol. 2004;22:699-706.

45. Xie F, Thumboo J, Fong KY, Lo NN, Yeo SJ, Yang KY, et al. Direct and indirect costs of osteoarthritis in Singapore: a comparative study among multiethnic Asian patients with osteoarthritis. J Rheumatol. 2007;34:165-71.

46. A C, Gupte C, Akhtar K, Smith P, Cobb J. The Global Economic Cost of Osteoarthritis: How the UK Compares. Arthritis. 2012;2012:698709. https://doi.org/10.1155/2012/698709.

47. Xie F. The need for standardization: a literature review of indirect costs of rheumatoid arthritis and osteoarthritis. Arthritis Rheum. 2008:59(7):1027-33.

48. Jonsson D, Husberg M. Socioeconomic costs of rheumatic diseases: Implications for technology assessment. Int J Technol Assess Health Care. 2000;16:1193-200.

49. Fautrel B, Guillemin F. Cost of illness studies in rheumatic diseases. Curr Opin Rheumatol. 2002;14(2):121-6. Review

50. Schofield DJ, Shrestha RN, Percival R, Passey ME, Callander EJ, Kelly SJ. The personal and national costs of lost labour force participation due to arthritis: an economic study. BMC Public Health. 2013;13:188.

51. Schofield DJ, Shrestha RN, Percival R, Passey ME, Callander E, Kelly S. The personal and national costs of CVD: impacts on income, taxes, government support payments and GDP due to lost labour force participation. Int J Cardiol. 2013;166(1):68-71

52. Schofield DJ, Cunich MM, Shrestha RN, et al. The economic impact of diabetes through lost labour force participation on individuals and government: evidence from a microsimulation model. BMC Public Health. 2014;14(1):220.

53. Schofield DJ, Shrestha RN, Percival R, et al. The personal and national costs of mental health conditions: impacts on income, taxes, government support payments due to lost labour force participation. BMC Psychiatry. 2011;11:72.

54. The 2015 Pension Adequacy Report: current and future income adequacy in old age in the EU. European Commission. Directorate-General for Employment, Social Affairs and Inclusion. Social Protection Committee.

55. Gouveia N, Rodrigues AM, Ramiro S, et al. EpiReumaPt: how to perform a national population based study - a practical guide. Acta Reumatol Port. 2015;40:128-36

56. Ramiro S, Canhao H, Branco JC. EpiReumaPt Protocol - Portuguese epidemiologic study of the rheumatic diseases. Acta reumatologica portuguesa. 2010;35(3):384-90. 